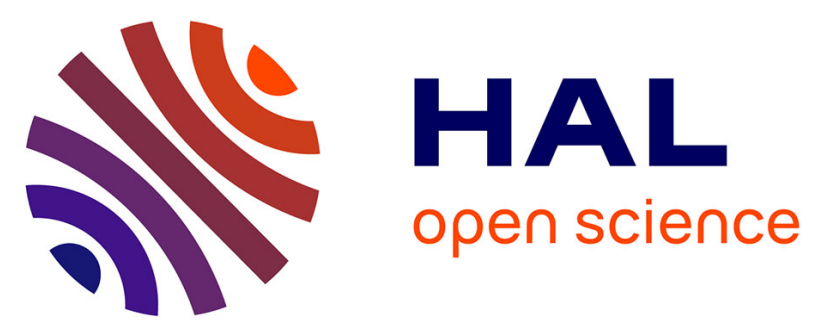

\title{
Mise en évidence in vitro d'effets toxiques entre Ustilago scitaminea Syd. et des cals de canne à sucre; influence de deux facteurs de croissance sur les phénomènes observés
}

\author{
Jean-Pierre Peros, Pierre Chagvardieff, Florence Paulet
}

\section{To cite this version:}

Jean-Pierre Peros, Pierre Chagvardieff, Florence Paulet. Mise en évidence in vitro d'effets toxiques entre Ustilago scitaminea Syd. et des cals de canne à sucre; influence de deux facteurs de croissance sur les phénomènes observés. Agronomie, 1983, 3 (7), pp.629-634. hal-00884552

\section{HAL Id: hal-00884552 \\ https://hal.science/hal-00884552}

Submitted on 1 Jan 1983

HAL is a multi-disciplinary open access archive for the deposit and dissemination of scientific research documents, whether they are published or not. The documents may come from teaching and research institutions in France or abroad, or from public or private research centers.
L'archive ouverte pluridisciplinaire $\mathbf{H A L}$, est destinée au dépôt et à la diffusion de documents scientifiques de niveau recherche, publiés ou non, émanant des établissements d'enseignement et de recherche français ou étrangers, des laboratoires publics ou privés. 


\title{
Mise en évidence in vitro d'effets toxiques entre Ustilago scitaminea Syd. et des cals de canne à sucre ; influence de deux facteurs de croissance sur les phénomènes observés
}

\author{
Jean-Pierre PEROS $\left(^{*}\right)$ \& Pierre CHAGVARDIEFF \\ avec la collaboration technique de Florence PAULET \\ I.R.A.T.-G.E.R.D.A.T., B.P. 5035 F 34032 Montpellier Cedex.
}

RÉSUMÉ

\begin{abstract}
Une culture in vitro associant Ustilago scitaminea Syd. et des cals de son hôte Saccharum sp. est réalisée en plaçant les tissus du faisceau foliaire de plantes malades sur un milieu de Murashige et Skoog modifié renfermant $3 \mathrm{mg} / \mathrm{l}$ d'acide 2-4 dichlorophénoxy acétique $(2-4 \mathrm{D})$. Les cals obtenus se distinguent des cals cxempts du parasite par une croissance ralentie et une réponse différente à l'équilibre kinétine/2-4 D du milieu.

L'effet inhibiteur du champignon est confirmé en le maintenant à distance du cal dans une même boîte de culture. A l'aide de cette méthode, différents génotypes de l'hôte sont testés mais il ne semble pas que le phénomène mis en évidence in vitro soit lié à la sensibilité au charbon de la plante entière.

L'hypothèse d'une excrétion par le champignon de substances agissant sur la croissance du cal est retenue ; ces excrétats pourraient avoir une activité de type cytokinine. Des excrétions du cal, sans doute de nature phénolique, limitent réciproquement la croissance fongique ; celle-ci est également affectée par le 2-4 D mais ne l'est pas par la kinétine aux concentrations utilisées.
\end{abstract}

Mots clés additionnels: Charbon de la canne à sucre, saccharum sp., physiopathologie, culture in vitro, Acide 2-4 dichlorophénox yacétique (2-4 D), kinétine.

Toxic effects between Ustilago scitaminea Syd. and sugarcane callus in vitro ; effect of two growth factors.

In vitro cultures associating Ustilago scitaminea Syd. with callus from its host Saccharum sp. were obtained from young leaf tissues of infected plants placed on a modified Murashige-Skoog medium containing $3 \mathrm{mg} / \mathrm{l}$ of 2,4-dichlorophenoxyacetic acid (2,4-D). This callus was marked off from parasite-free callus by reduced growth and different response to the kinetin/2,4-D balance of the medium.

The inhibitory effect of the fungus was confirmed by placing it at some distance from the callus in the same Petri dish. Different genotypes of the host were tested by this method but there was no apparent linkage between the in vitro phenomenon and the susceptibility of the whole plant to smut.

It is suggested that the fungus secretes products acting on callus growth; these secretions could have a cytokinin-like activity. Products from the callus, probably phenolic compounds, could reciprocally restrict fungal growth which was also affected by the tested concentrations of 2,4-D but not of kinetin.

Additional key words : Sugarcane smut, saccharum sp., In vitro culture, physiopathology, 2-4 dichlorophenoxyacetic acid $(2,4-D)$, kinetin.

\section{INTRODUCTION}

Dans la plupart des régions où est cultivée la canne à sucre (Saccharum sp.) sévit un charbon très redouté causé par Ustilago scitaminea Sydow. Le champignon, biotrophe, provoque des perturbations de croissance chez la plante

(*) Adresse actuclle : 1.R.A.T.-REUNION F 97487 St-Denis Cedex hôte, entraînant de graves chutes de production. Après une période d'incubation qui varie de 2 à 6 mois selon la sensibilité des variétés et les conditions climatiques, il apparaît, à l'extrémité des tiges malades, un sore charbonneux filiforme très caractéristique (ANTOINE, 1961). L'action du parasite sur le développement de la plante et l'existence de certains symptômes secondaires permettent de supposer que l'équilibre en facteurs de croissance de l'hôte est perturbé par U. scitaminea (BYTHER \& STEINER, 1974 ; PEROS, 1981). 
Depuis les travaux de MOREL (1948), la technique consistant à cultiver in vitro les parasites avec des tissus de leurs plantes hôtes est apparue intéressante non seulement pour la multiplication de parasites obligatoires (INGRAM, 1973), mais également pour des études de physiopathologie. Ainsi, il a pu être démontré une prototrophie pour la kinétine des cals de Brassica sp. infectés par Plasmodiophora brassicae Wor. (RedDy \& Williams, 1970). Batcho \& DuboIS (1976), pour leur part, ont mis en évidence un effet toxique d'excrétats d'Ustilago violacea (Pers.) Roussel sur le développement de colonies tissulaires et cellulaires de Silene alba.

A partir des premières tentatives de NICKELL (1964), la culture in vitro de la canne à sucre a connu un rapide développement : elle est désormais parfaitement maîtrisée (HEINZ et al., 1977). Des cultures associées entre des cals de Saccharum sp. et des microorganismes ont été réalisées: CHEN et al. (1979) ont obtenu des cals porteurs de Sclerospora sacchari Miyake à partir de cannes atteintes de mildiou; par ailleurs une bactérie clu genre Azospirillum se maintient dans des cals en croissance (VASIL et al., 1979).

C'est pourquoi, il nous est apparu possible et utile de mener une étude in vitro visant à mieux comprendre la physiopathologie de la maladie du charbon de la canne à sucre. Nous nous proposons d'obtenir des cals renfermant $U$. scitaminea et de comparer leur développement à celui de cals exempts du parasite ; en plaçant à distance l'un de l'autre, dans une même boîte de culture, un cal sain et le champignon, nous essayerons ensuite de préciser les effets du parasite sur les cellules de son hôte. Simultanément, nous analyserons l'influence des substances artificielles de croissance du milieu de culture sur les phénomènes observés.

\section{MATÉRIEL ET MÉTHODES}

\section{A. Matériel végétal}

Sept variétés commerciales de canne à sucre provenant de la serre de quarantaine de l'I.R.A.T. à Montpellier ont été utilisées. Il s'agit d'hybrides interspécifiques complexes du genre Saccharum multipliés végétativement. Ces clones présentent différents niveaux de résistance au charbon (ANONYME, 1977; BAUDIN, 1980)

- « NCo $310 », ~ « R 469$ », «N $55805 », ~ «$ Co $6415 »$ : sensibles ;

— «Co 421 », «Co 449 », « CB 4647 » : tolérants ;

— «Co $1230 »$ : sensibilité non connue.

Les plantes sont entretenues selon la technique utilisée dans la quarantaine (BAUDIN, 1978).

L'inoculation de "NCo 310 " est réalisée avec un isolat du parasite obtenu sur « NCo 310 » en Côte-d'Ivoire. Pour toutes les autres expériences, nous avons utilisé des téliospores récoltées sur la variété «HJ 5741 » en Guadeloupe. Les spores sont conservées au froid $\sec \left(4^{\circ} \mathrm{C}\right)$ (LEU, 1972).

\section{B. Inoculation des boutures}

Les boutures de " $\mathrm{NCo} 310$ " sont mises à prégermer en conditions humides pendant $24 \mathrm{~h}$ à $30^{\circ} \mathrm{C}$ à l'obscurité. Une suspension concentrée de téliospores $(3 \mathrm{mg} / \mathrm{ml})$ est badigeonnée sur la base scarifiée des pousses débarrassées de la

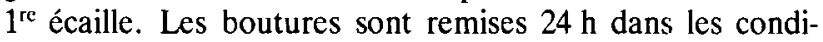
tions de la prégermination.

\section{Détection du parasite dans les tissus de la plante}

Les tissus des jeunes feuilles enroulées, les bases de gaines et les bourgeons axillaires sont traités au lactophénol (acide lactique : 1, glycérine : 1, phénol: 1 , eau : 5 en poids) pendant $1 \mathrm{~h}$, à $110^{\circ} \mathrm{C}$, à l'autoclave. Les échantillons sont ensuite colorés dans du lactophénol renfermant 0,05 p. 100 en poids de bleu de méthyle en les portant $5 \mathrm{mn}$ à ébullition. Après rinçage dans le lactophénol, l'observation microscopique des tissus dans de la glycérine permet de repérer facilement le mycélium d'U. scitaminea (DUARTE \& TOKESHI, 1977 ; TCHING, 1979).

\section{Culture in vitro des tissus végétaux}

\section{Obtention de cals sains}

Les faisceaux foliaires de plantes saines âgées de 2 à 4 mois sont coupés transversalement en tronçons de $5 \mathrm{~mm}$ de hauteur. Ceux-ci sont placés sur un milieu gélosé de Murashige \& Skoog (1962) renfermant $3 \mathrm{mg} / \mathrm{l}$ d'acide 2-4 dichlorophénoxyacétique (LIU et al., 1972). Après leur initiation ( 3 semaines), les cals sont séparés des tissus chlorophylliens puis repiqués et multipliés sur ce même milieu.

\section{Obtention de cals infectés}

Les jeunes feuilles enroulées des plantes malades de "NCo 310 ", âgées de 2 mois, présentent dans leur phloème le mycélium parasite. Il nous est donc apparu possible d'obtenir des cals contenant $U$. scitaminea en mettant en culture le faisceau foliaire des plantes malades selon le protocole utilisé pour la production de cals sains. La culture obtenue est dite «associée ".

\section{E. Culture in vitro dissociée du cal et du champignon}

Des cultures mycéliennes monotéliosporées sont obtenues sur milieu PDA (Difco) ou Trione (TrIONE, 1964). Après une semaine à $27^{\circ} \mathrm{C}$, les cultures sont délitées dans de l'eau stérile et la suspension sert à ensemencer des boîtes de Petri $(\varnothing 56 \mathrm{~mm})$ renfermant le milieu de base pour la culture des cals et diverses quantités de kinétine et de 2-4 D. Des gouttes de 2,5 $\mu$ de la suspension (pipette GILSON P20) sont disposées aux 4 points cardinaux de la boîte à proximité du bord. Un cal sain est ensuite déposé au centre de la boîte. La croissance faible des cultures mycéliennes, qui se transforment avec le temps en cultures sporidiales, ne permet à aucun moment un contact physique entre le cal et le champignon. La culture obtenue est dite «dissociée».

\section{F. Mesure de la croissance des cals}

Les différentes cultures sont placées dans une chambre climatisée dont l'alternance de la température $\left(20-25^{\circ} \mathrm{C}\right)$ est synchronisée avec une photopériode de $12 \mathrm{~h}\left(125 \mu \mathrm{Em}^{-2}\right.$ $\mathrm{s}^{-1}$ ). Le poids de matière fraîche (PF) des cals est mesuré avant la mise en culture puis après 3 semaines. L'accroissement relatif du PF (p. 100 du PF initial) entre les 2 dates sert à évaluer la croissance. Lorsque les hypothèses de base de l'analyse de covariance sont respectées, celle-ci est menée sur les PF; elle présente l'avantage d'ajuster les poids finaux en fonction des poids initiaux des cals. 


\section{G. Mesure de la croissance du champignon}

Les 4 colonies de chaque boîte des cultures dissociées se présentent sous la forme de croûtes facilement détachables du support gélosé. Une fois récoltées, elles sont pesées puis séchées à $60^{\circ} \mathrm{C}$ pendant $72 \mathrm{~h}$; leur poids de matière sèche est alors mesuré.

\section{RÉSULTATS}

\section{A. Evolution des cultures associées}

$\mathrm{Au}$ cours de la phase d'initiation des cals, U. scitaminea est apparu sur la majorité des explants issus de 4 des 10 plantes malades utilisées. Ensuite, au début de la multiplication, la sortie du parasite s'est manifestée de façon synchrone pour tous les cals d'une $5^{\mathrm{e}}$ plante. Pour les 5 dernières plantes et après 2 repiquages, la plupart des cultures étaient recouvertes et entourées par la forme sporidiale (cellules haploïdes) du champignon.

Ainsi l'évolution des cultures associées se caractérise par la sortie d'U. scitaminea à la surface des tissus infectés suivie d'une croissance saprophytique (mycélienne ou sporidiale) aux alentours du cal. Le délai qui précède ce phénomène apparaît différent selon la plante d'origine des cultures associées. Considérant que le champignon s'était partiellement affranchi du cal et que la masse fongique externe pouvait gêner les pesées nous n'avons pas mesuré la croissance de telles cultures.

\section{B. Comparaison des cultures associées et des cals sains.} Influence de l'équilibre kinétine/2-4 D (tabl. 1)

Les cals issus de plantes saines et malades sont repiqués, après leur multiplication, sur le milieu de base renfermant différentes quantités de kinétine et de 2-4 D. La comparai- son des accroissements relatifs du PF pour les divers traitements montre un effet des divers équilibres kinétine/2$4 \mathrm{D}$ sur la croissance des 2 types de cals. Par ailleurs, selon le milieu, le champignon peut être inhibiteur (milieux $(0 / 0)$, $(0 / 3),(0 / 30),(0,3 / 0)$ et $(30 / 30))$ ou stimulant (milieux $(0,3 / 3)$ et $(3 / 30))$ de cette croissance ; il peut aussi n'avoir aucune influence apparente sur celle-ci (les 6 autres milieux). Nous pouvons remarquer qu'un effet bénéfique du champignon s'observe lorsque les quantités de kinétine et de 2-4 D sont présentes dans la proportion de 1 pour 10 .

En l'absence de quelques données concernant le lot infesté (voir III, $\S \mathrm{A}$ et tabl. 1), l'analyse statistique ne porte que sur 3 des répétitions. Elle met en évidence un effet dépressif du champignon, le PF (tous milieux confondus) des cultures associées étant inférieur à celui des cals sains, et confirme l'influence de la composition du milieu. L'absence d'interaction cal $\times$ milieu signifie que le classement des poids moyens des 2 types de cal ne peut être considéré globalement comme dépendant de l'équilibre kinétine/2-4 D contrairement à ce que laisse supposer l'observation des taux d'accroissement.

\section{Effets à distance du champignon sur la croissance des cals. Influence de l'équilibre kinétine/2-4 D}

Les résultats consignés dans le tableau 2 montrent que la culture dissociée entraîne un ralentissement de la croissance des cals. Le phénomène ne peut être mis en évidence qu'avec les milieux propices à cette croissance. Effectivement, en l'absence de 2-4 D, le poids de matière fraîche des cals n'est pas influencé par la présence du champignon. Celle-ci ne permet pas de distinguer un équilibre kinétine/2$4 \mathrm{D}$ plus favorable qu'un autre : le parasite empêche la mise en évidence de l'action stimulante du 2-4 D et de l'effet inhibiteur de la kinétine à $3 \mathrm{mg} / \mathrm{l}$. Ces réponses différentes des cals au milieu en l'absence ou en présence du champi-

TABLEAU 1

Croissance des cals sains et infectés par U. scitaminea de la variêté "NCo310 " en fonction des concentrations en kinétine et 2-4D du milieu de culture.

Growth of healthy and U. scitaminea infected callus from the variety " NCo310" according to the concentrations of kinetin and 2,4-D in the culture medium.

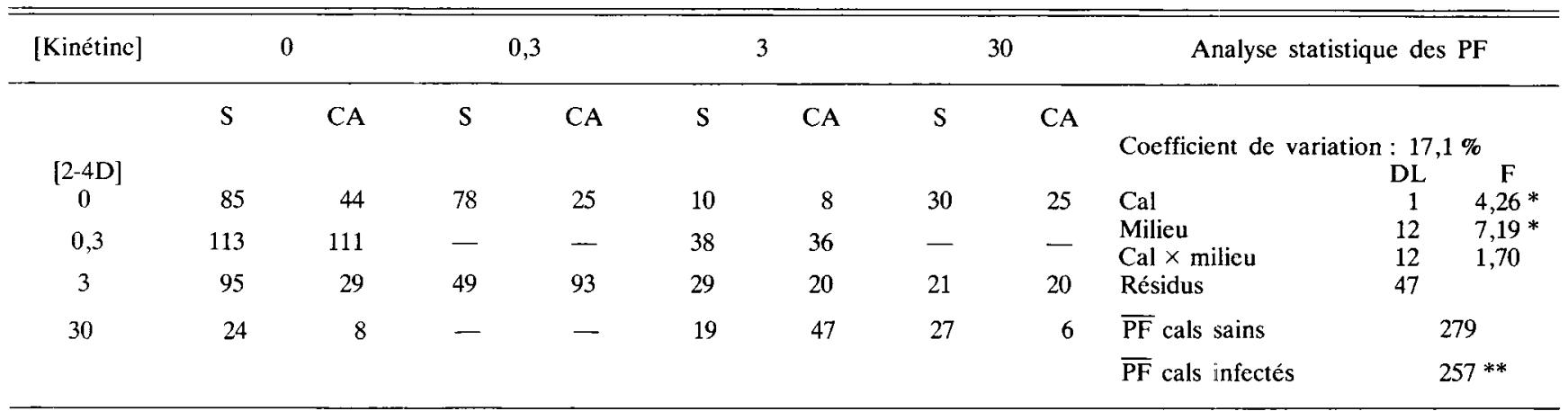

PF : Poids de matière fraîche en $\mathrm{mg}$.

$S$ : Accroissement relatif du $\mathrm{PF}$ des cals sains.

$\mathrm{CA}$ : Accroissement relatif du PF des cultures associées.

[] : Concentration en $\mathrm{mg} / \mathrm{l}$.

- : Traitcment non réalisé.

DL : Degré de liberté.

F : Test de Fischer.

$\overline{\mathrm{PF}}$ : Moyennes ajustées des poids finaux de matière fraîche en $\mathrm{mg}$.

* : Test F significatif au seuil 5 p. 100.

**: Moyenne différente au seuil 5 p. 100 (test de Duncan).

A la mise en culture, les cals sains et infectés sont âgés de 9 semaines et ont un PF moyen de $182 \pm 43$ mg; 5 répétitions pour le calcul des accroissements relatifs; 3 répétitions pour l'analyse statistique des PF. 
TABLEAU 2

Effets en culture dissociée d'U. scitaminea et des concentrations en kinétine et 2-4D du milieu sur la croissance des cals de la variété "NCo310 ". Effect of a separate culture of U. scitaminea and of kinetin and 2,4-D concentrations on the growth of callus of variety "NCo310".

\begin{tabular}{|c|c|c|c|c|c|c|c|}
\hline \multirow[t]{2}{*}{ Champignon } & \multicolumn{2}{|c|}{ Absent } & \multicolumn{2}{|c|}{ Présent } & \multicolumn{3}{|c|}{ Analyse statistique des PF } \\
\hline & AR & $\overline{\mathrm{PF}}$ & AR & $\overline{\mathrm{PF}}$ & & & \\
\hline ([Kinétine $] /[2-4 \mathrm{D}])$ & & & & & Coefficient de vat & : 24 & \\
\hline$(0 / 3)$ & 254 & $360^{\circ}$ & 86 & $170^{\mathrm{a}}$ & & $\mathrm{DL}$ & F \\
\hline$(0,3 / 3)$ & 219 & $302^{a b}$ & 67 & $150^{a}$ & Champignon & 1 & $35,45^{*}$ \\
\hline$(3 / 3)$ & 169 & $264^{b}$ & 66 & $150^{\mathrm{a}}$ & Milieu & 4 & $8,73 *$ \\
\hline$(3 / 0)$ & 51 & $173^{c}$ & 51 & $149^{a}$ & Champ. $\times$ milieu & 4 & $6,05 *$ \\
\hline$(0 / 0)$ & 89 & $130^{\mathrm{c}}$ & 56 & $142^{\mathrm{a}}$ & Résidus & 30 & \\
\hline
\end{tabular}

$\mathrm{PF}:$ Poids de matic̀re fraîche en mg.

AR : Accroissement relatif du PF.

$\overline{\mathrm{PF}}$ : Moyennes ajustées des poids finaux de matic̀re fraîche $\mathrm{en} \mathrm{mg.}$

[]: Concentration en $\mathrm{mg} / \mathrm{l}$.

DL : Degré de liberté.

F : Test de Fischer.

$*:$ Test $\mathrm{F}$ significatif au seuil 5 p. 100.

Les $\overline{\mathrm{PF}}$ d'une même colonne suivis d'une même lettre sont identiques au seuil 5 p. 100 (test Duncan).

A la mise en culture, les cals sont âgés de 28 semaines et ont un PF moyen de $90 \pm 18 \mathrm{mg} ; 4$ répétitions par traitement.

gnon concrétisent l'interaction statistiquement significative entre les 2 facteurs.

La même expérience est menée avec le génotype «Co $1230 »$ (tabl. 3). La culture dissociée provoque une inhibition quasi complète de la croissance des cals, celle-ci n'étant bonne que sur le milieu $(0 / 3)$ dépourvu de parasite. Quant à la kinćtine, elle réduit, aux 2 concentrations testées, l'effet du 2-4 D.

\section{Effets à distance du cal sain sur le champignon. Influence de l'équilibre kinétine/2-4 D}

Lors de l'étude en culture dissociée réalisée avec la variété « NCo $310 »$, l'influence du cal sur $U$. scitaminea est mesurée. Tous milieux confondus, le cal réduit la croissance des colonies fongiques (tabl. 4). Inapparente pour le milieu

\section{TABLEAU 3}

Effets en culture dissociée d'U. scitaminca et des concentrations en kinétine et $2-4 D$ du milieu sur la croissance des cals de la variété "Co1230».

Effect of a separate culture of $U$. scitaminea and of kinetin and 2,4$D$ concentrations on the growth of callus of variety " Col230».

\begin{tabular}{ccc}
\hline Champignon & Absent & AR \\
\hline & AR & AR \\
\hline$([$ Kinétine] $][2.4 \mathrm{D}])$ & & \\
$(0 / 3)$ & 181 & 13 \\
$(0,3 / 3)$ & 89 & 7 \\
$(3 / 3)$ & 47 & - \\
$(3 / 0)$ & 53 & 22 \\
$(0 / 0)$ & 72 & - \\
\hline
\end{tabular}

AR : Accroissement relatif du poids de matière fraîche.

[] : Concentration en $\mathrm{mg} / \mathrm{l}$.

- : Traitement non réalisé.

A la mise en culture, les cals sont âgés de 23 semaines et ont un PF moyen de $55 \pm 13 \mathrm{mg}$; 8 répétitions par traitement.

\section{TABLEAU 4}

Effets en culture dissociée des cals de la variété "NCo310" et des concentrations en kinétine et $2-4 D$ du milieu sur la croissance $d$ 'U. scitaminea.

Effect of separate callus of variety "NCo310 " and of kinetin and 2,4-D concentrations on the growth of $\mathrm{U}$. scitaminea.

\begin{tabular}{ccccc}
\hline \hline Cal & \multicolumn{2}{c}{ Absent } & \multicolumn{2}{c}{ Présent } \\
\hline & PF & PS & PF & PS \\
\hline$([$ Kinćtinc] $][2-4 \mathrm{D}])$ & & & & \\
$(0 / 3)$ & 141 & 21 & 160 & 18 \\
$(0,3 / 3)$ & 133 & 19 & 98 & 14 \\
$(3 / 3)$ & 139 & 22 & 97 & 12 \\
$(3 / 0)$ & 208 & 30 & 180 & 20 \\
$(0 / 0)$ & 221 & 32 & 139 & 12 \\
\hline $\bar{m}$ & 168,4 & 24,8 & 134,8 & 15,2 \\
\hline
\end{tabular}

PF : Poids de matière fraîche d'une colonie en $\mathrm{mg}$.

PS : Poids de matière sèche d'une colonie en $\mathrm{mg}$.

[] : Concentration en $\mathrm{mg} / \mathrm{l}$.

$\overline{\mathrm{m}}$ : Moyenne pour les 5 milieux.

4 répćtitions par traitement.

$(0 / 3)$, cette action est en revanche très marquée pour $(0 / 0)$. Sur ce dernier, les cals se nécrosent en libérant des substances qui colorent la gélose (surtout aux alentours du cal et du champignon) et les colonies. En l'absence du cal, $U$. scitaminea est affecté par le 2-4 D mais ne semble pas sensible à la kinétine.

\section{E. Effets à distance du champignon sur les cals de différentes variétés (tabl. 5)}

Cette expérience s'effectue sur le milieu $(0 / 3)$ utilisé pour l'initiation et la multiplication des cals. L'effet dépressif du champignon sur la croissance des cals s'observe pour tous les génotypes testés bien que l'augmentation du PF soit très 
TABLEAU 5

Effet en culture dissociée d'U. scitaminea sur la croissance des cals de 6 variétés de canne à sucre. Effect of a separate culture of U. scitaminea on callus growth in 6 varieties of sugarcane.

\begin{tabular}{|c|c|c|c|c|c|c|c|}
\hline \multirow[t]{2}{*}{ Champignon } & \multicolumn{2}{|c|}{ Absent } & \multicolumn{2}{|c|}{ Présent } & \multicolumn{3}{|c|}{ Analyse statistique des $\mathrm{PF}$} \\
\hline & $\mathrm{AR}$ & $\overline{\mathrm{PF}}$ & AR & $\overline{\mathrm{PF}}$ & & & \\
\hline Variété & & & & & Coefficient de variatio & : $: 17$ & $7 \%$ \\
\hline Co 421 & 94 & $329^{\mathrm{a}}$ & 36 & $199^{a}$ & & & \\
\hline R 469 & 196 & $326^{a}$ & 25 & $195^{a b}$ & & DL & $\mathrm{F}$ \\
\hline N 55805 & 80 & $262^{b}$ & 30 & $194^{a b}$ & Champignon & 1 & $105,06^{*}$ \\
\hline Co 6415 & 44 & $221^{\mathrm{c}}$ & 1 & $158^{\mathrm{bc}}$ & Variété & 4 & $20,22 *$ \\
\hline CB 4647 & 18 & $189^{c}$ & 2 & $153^{\mathrm{bc}}$ & Champignon $\times$ variété & 4 & 5,18 * \\
\hline Co 449 & 160 & - & 40 & - & Résidus & 90 & \\
\hline
\end{tabular}

PF : Poids de matière fraîche en $\mathrm{mg}$.

AR : Accroissement relatif du PF.

$\overline{\mathrm{PF}}$ : Moyennes ajustées des poids finaux de matière fraîche en $\mathrm{mg}$.

- : Variété absente de l'analyse de covariance.

DL: Degré de liberté.

$\mathrm{F}:$ Test de Fischer.

*: Test F significatif au seuil 5 p. 100.

Les $\overline{\mathrm{PF}}$ d'une même colonnc suivis d'une même lettre sont identiques au seuil 5 p. 100 (test de Duncan).

A la mise en culture, les cals sont âgés de 16 semaines et ont un PF moyen de $159 \pm 37 \mathrm{mg}$; 10 répétitions par traitement.

différente selon l'origine des cals. Le classement des moyennes pour le milieu sans champignon indique les aptitudes de chacune des variétés pour la prolifération de leurs cals. C'est ainsi que les aptitudes des variétés «Co 421 » et « R 469 » s'avèrent nettement supérieures à celles des variétés «Co 6415 » et «CB 4647 », « N 55805 » adoptant un comportement intermédiaire. Le classement des $\overline{\mathrm{PF}}$ obtenus en présence du parasite est semblable mais fait apparaître des différences moins importantes entre les variétés. L'interaction statistique rend compte de ce dernier phénomène.

\section{DISCUSSION}

Contrairement à LEU (1971), nous avons observé le mycélium d'U. scitaminea dans le phloème des jeunes feuilles enroulées de cànne à sucre malades. La mise en culture in vitro de ces tissus permet d'obtenir une culture associée entre le champignon et les cals de son hôte. Le champignon colonise ensuite les surfaces du cal et du milieu avec un délai qui semble lié à la plante mise en culture in vitro. Pour expliquer ce dernier phénomène on peut supposer que la colonisation parasitaire du faisceau foliaire ou que la croissance des cals sont différentes selon les individus malades.

L'étude de l'évolution du poids de matière fraîche des cultures associées comparativement à celle des cals sains montre qu'U. scitaminea réduit la croissance des cals tous milieux confondus. Les exigences vis-à-vis des facteurs de croissance ont, semble-t-il, été perturbées par le parasite puisque le classement arithmétique de l'accroissement relatif du PF des 2 types de cals est différent selon l'équilibre kinétine/2-4 D du milieu. En particulier lorsque le 2-4 D est en quantité 10 fois plus importante que la kinétine, la présence du parasite s'avère bénéfique à la croissance des cultures associées.

Bien que la technique des cultures associées nous permette de révéler une action d' $U$. scitaminea sur les cals de son hôte, l'instabilité des cultures rend leur utilisation délicate. De plus, l'élimination des cultures donnant rapidement un développement saprophytique du champignon peut nous amener à utiliser des cultures contenant peu de mycélium parasite pour les comparaisons de croissance. Cette remarque permet de révéler un autre inconvénient de la culture associée : l'incapacité de contrôler la quantité mycélienne agissant sur le cal.

Les difficultés précédentes peuvent être résolues en plaçant le champignon à distance des cals dans une même boîte de culture. A l'aide de cette méthode, la réduction par le champignon de la croissance des cals est très nettement confirmée et n'apparaît pas si le 2-4 D est absent du milieu de culture. En revanche, l'action bénéfique observée en culture associée sur le milieu $(0,3 / 3)$ n'est plus visible. Cette divergence entre les 2 méthodes peut s'expliquer par l'utilisation de cals d'âge et d'origine différents, mais on peut invoquer avec plus de vraisemblance la quantité de mycélium ou le métabolisme fongique impliqués dans les 2 expériences.

Le cal étant affecté à distance par $U$. scitaminea, nous pouvons penser que des substances diffusent à travers la gélose depuis le champignon jusqu'au cal. BAтchо \& DUBOIS (1976) retiennent également cette hypothèse après avoir montré que l'action dépressive d' $U$. violacea sur les cals de Silene alba n'est pas due à un appauvrissement du milieu en composés nutritifs ni à une modification de $\mathrm{pH}$.

Quels peuvent être les produits fongiques responsables des phénomènes observés ? Il peut s'agir, tout d'abord, de facteurs de croissance qui, en perturbant l'équilibre hormonal des cals, inhiberaient leur croissance. Cette perturbation déjà suspectée lors de l'étude en culture associée, se caractériserait en culture dissociée par une insensibilisation des cals au 2-4 D, ainsi :

- la croissance des cals des variétés «NCo 310 » et «Co 1230 » en présence de 2-4 D et du champignon est similaire à celle obtenue en l'absence de ces derniers (tabl. 2 et 3 );

- les 6 variétés testées simultanément (tabl. 5) sont mieux discriminées par le 2-4 D en l'absence du champignon qu'en sa présence. 
Comme l'apport de kinétine s'accompagne également d'une diminution de l'effet du 2-4 D, on peut supposer qu' $U$. scitaminea sécrète des substances de type cytokinines. Le fait que les cals de la variété «Co 1230 » aient une réponse plus prononcée à la fois à la kinétine et au champignon que ceux de la variété « NCo 310 » conforte cette hypothèse. Par ailleurs, les balais de sorcières et les galles observés sur les cannes atteintes de charbon (BYTHER \& STEINER, 1974. ; PEROS, 1981) peuvent faire penser à une intervention des cytokinines: celles-ci sont produites par $U$. maydis en culture et dans les tissus infectés du maïs (Mills \& VAN STADEN, 1978).

Des métabolites non hormonaux peuvent aussi causer la toxicité observée. Ainsi, les polyalcools érythrytol et mannitol sont produits par $U$. scitaminea mais sont absents du métabolisme de la canne à sucre saine (PEROS, 1981). Des toxines fongiques freinent la croissance des cals de plantes hôtes: Helminthosporium maydis pour le maïs (GENGENBACH \& GREEN, 1975) et $H$. sativum pour le froment et l'orge (DUTRECQ, 1981). Dans ces exemples, il existe cependant une concordance entre l'effet in vitro et la sensibilité de la plante entière, ce qui ne semble pas être le cas du couple $U$. scitaminea-Saccharum sp. puisque $U$. scitaminea a influencé de la même manière des cals provenant de variétés de sensibilité différente au champ. De plus, l'allongement excessif des entrencuds avant et au cours de la sporulation du pathogène (PEROs, 1981) - qui est sans doute permis par une division et une élongation cellulaires accrues - n'est pas de même nature que la réponse du cal. Ceci nous incite à penser que les synthèses fongiques, si elles ont lieu également in vivo, doivent avoir un rôle physiologique complexe à l'intérieur de la plante malade et non une action toxique (cas des Helminthosporium). Les produits mis en jeu seraient plus vraisemblablement des substances de croissance (cytokinines ou autres) qui pourraient à la fois agir sur le développement de la plante entière et gêner la croissance in vitro des cals.

Simultanément, nous avons noté que le cal pouvait agir à distance sur la croissance du champignon. Les cellules de la plante hôte ont ainsi, in vitro, la capacité de limiter le développement du parasite. Les cals de canne à sucre excrétant des phénols (CHAGVARDIEFF et al., 1981), il est permis de supposer que les substances colorées que nous avons observées au cours de notre expérimentation sont de nature phénolique et responsables de l'inhibition du champignon. Selon la variété, le spectre phénolique actif in vitro pourrait être ainsi directement relié aux difficultés de progression du parasite dans les tissus hôtes. $U$. scitaminea est également sensible au 2-4 D mais insensible à la kinétine aux concentrations utilisées. Toutefois, les effets toxiques du cal et du 2-4 D sur le parasite ne modifient pas l'action inhibitrice à distance de ce dernier sur le cal.

Reçu le 8 octobre 1982 Accepté le 5 mars 1983.

\section{REMERCIEMENTS}

Les autcurs expriment leur reconnaissance à M. WEIL (Méthodologie/I.R.A.T.) pour l'aide apportée dans la conduite des calculs statistiques. lls remercient M. Le Professeur Chevaugeon (Faculté d'Orsay) ainsi que MM. Baudin, Mauboussin et Girard (I.R.A.T.) pour leurs critiques constructives.

\section{RÉFÉRENCES BIBLIOGRAPHIQUES}

Anonyme, 1977, Variety notes. Copersucar, $3^{\mathrm{e}}$ éd., $50 \mathrm{p}$. Antoine R., 1961. Smut in Sugarcane diseases of the World, 1, 326354. Ed. Martin J. P., Abbott E. V., Hughs C. G., Elsevier

Batcho M., Dubois J., 1976. Etude de quelques effets de l'Ustilago violacea sur la croissance de colonies tissulaires et de suspensions cellulaires de Silene alba. Bull. Soc. Bot. Fr., 28/29, 51-59.

Baudin P., 1978. Rapport annuel de la serre de quarantaine canne à sucre. IRAT/DDC, 25, $15 \mathrm{p}$.

Baudin P., 1980. Pathologie de la canne à sucre en Haute-Volta. IRAT/DDC, 52, 21 p.

Byther R. S., Steiner G. W., 1974. Unusual smut symptoms of sugarcane in Hawaii. Plant Dis. Rep., 58, 401-405.

Chagvardieff P., Bonnel E., Demarly Y., 1981. La culture in vitro de tissus somatiques de canne à sucre (Saccharum sp.). Agron. trop., 36, 266-278.

Chen W. H., Liu M. C., Chao C. Y., 1979. The growth of sugarcane downy mildew fungus in tissue culture. Can. J. Bot., 57, 528533.

Duarte M. L. R., Tokeshi, 1977. Inoculation of sugarcane seedlings for selection of resistance to Ustilago scitaminea. Proc. ISSCT, XVI, 1-11.

Dutrecq A., 1981. Studics of the effects of toxic preparations of Helminthosporium sativum $\mathrm{P} . \mathrm{K}$. and $\mathrm{B}$. on barley and wheat, and perspectives of in vitro selection of these cereals. Agronomie, 1, 167-176.

Gengenbach B. G., Green C. E., 1975. Selection of T cytoplasm maize callus cultures resistant to Helminthosporium maydis race $\mathrm{T}$ pathotoxin. Crop Sci., 15, 645-649.

Heinz D. J., Krishnamurti M., Nickell L. G., Maretzki A., 1977. Cell tissue and organ culture in sugarcane improvement in Plant cell, tissue and organ culture, 1-17, Ed. J. Reinert, Y. P. S. Bajaj. Springer Verlag.

Ingram D. S., 1973. Growth of plant parasites in tissue culture in Plant tissue and cell culture, 382-421. Ed. H. E., Street, Univ. California Press. Berkeley and Los Angeles.
Leu L. S., 1971. Culmicolous smut of sugarcane in Taiwan. II. Pathological histology of diseased cane. Plant Prot. Bull., 13, 6-11. Leu L. S., 1972. Culmicolous smut of sugarcane in Taiwan. III. Germination and storage of teliospores, and compatibility of Ustilago scitaminea. Rep. Taiwan Sug. Exp. Stat., 56, 37-45.

Liu M. C., Haung Y. J., Shin S. C., 1972. The in vitro production of plants from several tissues of Saccharum species. J. Agric. Assoc. China, 77, 52-58.

Mills L. J., Van Staden J., 1978. Extractions of cytokinins from maize smut tumors of maize and Ustilago maydis cultures. Physiol. Plant Pathol., 13, 73-80.

Morel G., 1948. Recherches sur la culture associée de parasites obligatoires et de tissus végétaux. Ann. Epiphyt. 14, 1-112.

Murashige T., Skoog F., 1962. A revised medium for rapid growth and bioassays with tobacco tissue culture. Physiol. Plant, 15, 473497.

Nickell L. G., 1964. Tissue and cell cultures of sugarcane, another research tool. Hawaian Planter's Record, 57, 223-229.

Peros J. P., 1981. Contribution à l'étude du charbon de la canne à sucre (Saccharum sp.) causé par Ustilago scitaminea Syd. Variabilité du parasite et physiologie de l'infection. Thèse de $3^{\mathrm{e}}$ cycle, Université d'Orsay, $93 \mathrm{p}$.

Reddy M. N., Williams P. H., 1970. Cytokinin activity in Plasmodiophora brassicae infected cabbage tissue culture. Phytopathology, 60, 1463-1465

Tching L., 1979. Etude de la résistance de plantules de canne à sucre à Ustilago scitaminea Syd. Mémoire de D.E.A., Université d'Orsay, 15 p.

Trione E. J., 1964. Isolation and in vitro culture of the wheat bunt fungi Tilletia caries and Tilletia controversa. Phytopathology, 54, 592-596.

Vasil V. I., Vasil K., Zuberrer D. A., Hubbel D. H., 1979. The biology of Azospirillum sugarcane association. I. Establishment of the association. Z. Pflanzenphysiol., 95, 141-147. 